\title{
eLyra
}

\section{O desejo é um lago azul: Leonilson, a imagem e o poema}

\author{
Gustavo Silveira Ribeiro \\ Universidade Federal de Minas Gerais
}

Resumo: O ensaio pretende analisar os modos como a obra plástica e visual de José Leonilson se apropria da linguagem verbal, construindo-se a partir do hibridismo e do cruzamento de gêneros e fronteiras. Lida aqui fundamentalmente como elaboração poética, a obra do artista revela a porosidade, no panorama contemporâneo, das fronteiras entre arte e literatura, ambas movendo-se, para falar com e a partir de Rosalind Krauss, em direção a um campo expandido de ação.

Palavras-chave: Leonilson, artes visuais, poesia brasileira contemporânea, hibridismo, campo expandido

\begin{abstract}
The essay aims to analyze the way José Leonilson's plastic and visual art work appropriates the verbal language and build itself from the hybridism and also from the crossover between genders and borders. The artist's art work will be read in this essay fundamentally as a poetic elaboration. It will be noticed, based on the contemporary panorama, that Leonilson's work reveals an opening in art and literature frontier and that both of them are making an attempt to establish a dialogue with Rosalind Krauss and her work toward an expanded action field.
\end{abstract}

Keywords: Leonilson, visual art, contemporary Brazilian poetry, hybridism, expanded field 


\section{Desvio, fuga, expansão}

Jean-Luc Nancy, num texto justamente célebre, Resistance de la Poésie, afirmou que a poesia carrega em si, constitutivamente, um paradoxo, uma torção de origem que a desloca sempre, que a torna problemática (em muitos sentidos), seja em relação às leis de ferro do mercado, seja em relação às normatizações comuns à linguagem e ao pensamento. Segundo ele, "a poesia não coincide consigo mesma: talvez seja essa não coincidência, essa impropriedade substancial, aquilo que faz propriamente a poesia" (Nancy 2005: 11). Curiosa afirmação: dela, um termo se destaca, quase vertiginoso: a impropriedade. A poesia seria imprópria, isto é, não adequada, capaz de desvirtuar moral ou ideologicamente, produtora de desequilíbrio formal e rebelião; e também, ao mesmo tempo, ela (a poesia) é, está distante do alcance e dos limites de qualquer propriedade, no duplo sentido que se esconde sob essa palavra: próprio, como se sabe, remete à posse e ao uso de um ser ou objeto, cujo fundamento se encontra no direito, instância reguladora da propriedade privada e estatal, das suas garantias e contrapartidas possíveis; de outro lado, no entanto, próprio indica a identidade, a imagem que o sujeito tem de si, o acordo que se estabelece entre aquilo que se é e o que se pode (ou se deseja) ser. Nesse sentido, é ao vasto campo da metafísica, e da ontologia em particular, que se liga o sentido desse termo, sua formulação conceitual.

Dividida entre essas duas instâncias (o direito, a ontologia), equidistante de cada uma delas, a poesia, segundo propõe Nancy, se constitui necessariamente na fuga, no deslizamento, no desencontro com todos os discursos, práticas e tradições que se cristalizam ao seu redor, buscando apreendê-la. Nem a reprodução infinita e alienada de si, como uma fórmula ou um gênero estanque, como quer a prescrição dogmática, nem a forma fácil e mercantil do texto leve, espécie de canção ligeira que teria o seu lugar (o seu nicho) entre os muitos produtos de uma sociedade de consumo: em qualquer dessas opções, o desencontro e a frustração às expectativas serão a saída da poesia, bem como uma potência de expansão permanente de seus próprios recursos, uma capacidade de sair de si e alargar os seus domínios técnicos e formais, assimilando modos, discursos e zonas de inserção que, antes, Ihe eram alheias. A mesma inquietude e desobediência formal da poesia é igualmente o seu coeficiente político e ético, na medida em que a um tipo de alargamento da experiência sensível se segue, como consequência e virtualidade, uma mesma energia de negação - que 
se dá a ver como recusa de um mundo codificado (afetos, formas da organização social, silêncios da linguagem e obstáculos ao trânsito dos corpos) e procura por modos novos de existência, maneiras outras de habitar a terra e participar da circulação ilimitada de seus saberes e recursos.

É isso o que vai afirmar, em outros termos, Alberto Pucheu, chamando de "apoesia" (Pucheu 2014: 249) essa força-forma que têm os textos poéticos contemporâneos, segundo argumenta, de escapar aos liames convencionais e crescer, ocupando espaços e superfícies distintas de si, dos lugares convencionalmente a ela reservados. Concentrado nas pichações e intervenções urbanas como a street art e o graffiti, o poeta e crítico do Rio de Janeiro busca refletir sobre os modos que tem a poesia de se construir como uma noção ambígua, uma espécie de campo de oscilação permanente (para falar com Derrida), segundo o qual a condição poética se afirma e põe em xeque ao mesmo tempo, desarmando, com isso, os instrumentos críticos tradicionais ao demandar do leitor/observador do fenômeno poético um novo ponto de vista e uma maneira distinta de compreender os seus objetos. Como se pode ver tanto em Nancy como no pesquisador brasileiro, é dessa condição desviante dessa propriedade, se poderia dizer, trazendo à tona outro sentido ao mesmo termo, dando outra volta no parafuso do pensamento filologicamente informado - que a poesia retira sua energia de invenção e crítica, sua capacidade de desestabilizar a língua e o saber.

Texto em fuga, a poesia caminha quase sempre para as margens e os limites da linguagem, do conhecimento, da pesquisa formal. Seu não lugar essencial a leva, como ficou dito, continuamente a alargar o campo de possibilidades de sua inserção, fazendo com que, mais do que em outros modos e práticas de escritura, as definições de gênero não possuam a mesma força normativa ou equivalente possibilidade descritiva. A poesia, nesse sentido, parece ecoar com enorme força as proposições de Jacques Derrida sobre o tema, especialmente expostas no ensaio La loi du genre (Derrida 1986). Ali, o filósofo vai propor que o gênero, qualquer gênero - literário, biológico ou de natureza sexual, por exemplo não deve ser entendido apenas como norma ou linha de corte, mas antes como memória e promessa, isto é, convite a um universo de possibilidades abertas e em devir, diálogo com tradições e formas passadas, verdadeira chave de reflexão crítica sobre a impureza originária e fundamental da literatura, dos discursos, da vida - da poesia em particular. Procurando 
pensar em termos de uma "lei da lei do gênero" (Derrida 1986: 5), ${ }^{1}$ o autor afirma que, em que pese a indicação ao resguardo e ao limite que a própria palavra "gênero" traz consigo, ao apontar sempre para a origem (um tipo qualquer de exercício de pensamento que parte em direção a uma genealogia qualquer), subjaz a ela, ao conceito mesmo de gênero, "um princípio de contaminação, uma lei de impureza, uma economia do parasita" (Derrida 1986: 5) que assinala a condição de estranhamento de si, o desencontro que define a poesia: do que se espera e ordena que ela seja, em pura repetição, ela desvia e perverte, confirmando uma rede de relações incertas que a desdobra desde os seus princípios irrastreáveis, afinal; onde se espera que ela esteja e se confine, ela se expande ou se retrai, encontrando-se, preferencialmente, no paradoxo de um não lugar, ou num ponto fora de si, em relação projetiva com outras formas de vida textual, em desacordo com seu nascimento projetado, os ordenamentos e instruções que daí devêm.

O mergulho decisivo em outras linguagens artísticas e modos expressivos, a frequentação às margens da linguagem, a condição mesma de impropriedade fazem com que o fenômeno poético não se dê a ver apenas nos seus nichos tradicionais de circulação e consumo, historicamente a voz e o livro, migrando desse modo para outros suportes e diferentes gestos criativos, ou ainda que se feche no circuito restrito de uma definição teórica previamente configurada, num espaço e numa forma textuais que assinalem, antes mesmo de sua emergência enquanto texto literário, o lugar que deve ocupar no mundo das letras e no vasto e intercambiável universo da eitura. O possível efeito de alargamento que aqui se pode ver e que no fundo está em jogo nas abordagens teóricas brevissimamente antes comentadas não deve ser lido apenas como resultado (direto ou indireto) de uma crise do poético - tema tão frequente da crítica e da própria poesia nos últimos 150 anos, pelo menos; ou ainda de um movimento de renovação e pesquisa estética vinculado ao Make it New! moderno, numa espécie de sobrevivência deslocada da inquietação vanguardista que tudo quer derrubar e fazer uma vez mais, em corpo novo e nunca antes visto. O que se coloca de fato em questão tem a ver com a elaboração, no horizonte da nossa contemporaneidade, de um conceito que dê conta, a partir de diferentes solicitações e metodologias, de algo que se poderia chamar "literatura expandida", para lembrar aqui o título e o eixo central do livro de Ana Pato (2013), resultado de sua pesquisa doutoral sobre 
a artista francesa Dominique Gonzalez-Foerster e suas relações e intertextos com o universo literário; ou ainda de uma "forma impertinente", móvel e mutante, em incorporação permanente de materiais, linguagens e experiências não poéticas (ou não literárias), conforme propõe, em mais de um momento, a ensaísta argentina Florencia Garramuño (p. ex. Frutos estranhos, 2014). O reconhecimento de que a paisagem literária vem se modificando velozmente impõe ao pensamento crítico a tarefa de lidar com novos objetos a partir também de novos instrumentos de reflexão, novo cenário de conceitos e formulações críticas que possam envolver a produção e a circulação de textos e objetos poéticos, lendoos a partir das demandas que colocam e não apenas das perguntas que outras obras e outro horizonte de reflexão antes propuseram.

Será portanto nesse esforço de avaliação e reproposição de definições que este ensaio pretende traçar, rapidamente e de modo introdutório, algumas linhas sobre o artista visual José Leonilson, nascido no Ceará, inventor de grande relevância na cena do fim dos anos 1980, desaparecido precocemente, em 1993, em decorrência da Aids. A partir do autor (e no que vão propor as suas muito diferentes obras), procuro observar como a poesia (no Brasil contemporâneo, mas não só) tem escapado de seus modos e circunstâncias particulares e se expandido para diferentes modos discursivos e práticas artísticas, fazendo com que a ideia de um outro lugar, um quase impossível fora-de-si, seja uma imagem conceitual adequada para descrever, com alguma acuidade, parte significativa e problemática da cena poética mais relevante do país.

\section{Presença da palavra}

Um dos artistas mais celebrados do país nos últimos anos, tendo reconhecida a sua presença (e influência) na obra de artistas decisivos da cena contemporânea brasileira e mesmo do exterior, Leonilson fez parte, inicialmente, da chamada Geração 80, grupo de artistas que, em meados daquela década, retomaram o caminho da pintura e das artes visuais, criando, às vezes em ateliês coletivos, pinturas de grandes dimensões e de cores fortes, em contraste, de certo modo, com a tendência conceitual e minimalista da arte brasileira das duas décadas anteriores. Nomes como Nuno Ramos e Paulo Pasta, por exemplo, fazem parte dessa mesma constelação, que reunia artistas e projetos estéticos 
heterogêneos, mas próximos uns dos outros pelo retorno à pintura e o uso (ainda que temporário) de certos procedimentos e técnicas comuns. Bastante mais conhecido - e estudado - por sua atuação no campo das artes plásticas, Leonilson deixou uma vasta obra que, cada vez mais, vem chamando a atenção de críticos e pesquisadores de outras áreas do conhecimento (psicanálise, queer studies, moda), e da literatura em particular. A incorporação da palavra escrita, seu uso e lugar particular nos trabalhos do autor (desenhos, gravuras, bordados, quadros de dimensões variadas e também um diário sonoro) dão margem a uma aproximação de campos e linguagens semelhante à que realizam os pesquisadores das intermidialidades e dos processos interartes. No entanto, acredito ser possível ler a sua obra como gesto (também) literário, no qual dispositivos poéticos e narrativos se colocam em pé de igualdade, num certo sentido, àqueles de natureza plástica e visual, configurando-se, entre outras coisas, como um espaço de produção textual.

Construída em torno de uma multiplicidade de formas, meios e linguagens, a obra de Leonilson sempre se afirmou como um espaço híbrido e impuro, no qual se mesclam a pintura de grandes dimensões, o bordado e a costura, pequenos desenhos, gravuras e instalações, nas quais matérias tão distintas quanto o veludo, espelhos, móveis, botões, lantejoulas e livros são usados de modo sutil, como que deslocado. Essa impureza de origem, a tendência à mescla de formas e texturas, fez com que o artista pudesse trazer para dentro de sua obra registros escritos (e falados) muito elaborados, dentre os quais se destacam poemas inteiros, versos ou fragmentos textuais. Todos eles existem como testemunhas da experiência, do gesto corporal que os criou: daí se cruzarem continuamente a grafia, o bordado e a pintura, três formas de inscrição manual, de produção de presença no universo da tela ou objeto. Há também uma espécie de forma-diário atravessando as fases finais do seu trabalho, feito através do registro da voz do artista, bem como das impressões sobre o cotidiano que ia distribuindo nas peças que compôs diariamente ao longo dos últimos anos de sua breve vida. Ler seus trabalhos a partir do arsenal crítico e teórico das Letras, da teoria da literatura especificamente, pode ser uma opção interessante, capaz de descortinar sentidos ainda pouco explorados da produção do artista, mas já previstos pela primeira recepção crítica do autor: para lembrar apenas um exemplo, Lisette Lagnado (no muito conhecido estudo São tantas as verdades) chamará o autor de "pescador 
de palavras" (cf. Lagnado 1998), ressaltando o lugar muito particular da literatura, da poesia mais precisamente, em seus trabalhos - dando ênfase também ao diálogo que manteve com artistas que, cada um a seu modo, também flertaram, na cena brasileira, com a palavra escrita: de modo especial, Arthur Bispo do Rosário, cujo surgimento, ou revelação, no fim dos anos 1980 muito teria impactado o autor, e Antônio Dias, de cuja constelação de letras e cores Leonilson se aproximou nos seus anos finais.

Mesmo sem poder recorrer, num ensaio como este, à completude multimidiática das peças originais, muitas delas realizações táteis e tridimensionais, é possível analisar alguns exemplos dos usos e apropriações da linguagem verbal feitas por Leonilson - os seus gestos criativos que traziam em seu bojo um saber e uma formulação literárias. Ainda que a forma do texto não possa mais ser descrita segundo os marcos teóricos (e de gênero) tradicionais da instituição literária, uma tentativa de reconfiguração e leitura já seria capaz de revelar alguns dos seus aspectos decisivos. No belíssimo quadro intitulado "Todos os rios", de 1988, o artista traz ao centro da tela/texto um conjunto de traços e linhas que formam, ao modo de um mapa de cores vivas, a imagem de rios que se encontram, em meio aos quais as palavras se acumulam e distribuem, ora evocando nomes de corpos d'água conhecidos, ora trazendo inscrições não descritivas, estranhas à lógica de uma carta hidrográfica por formarem uma sentença de sentido completo e de natureza metafórica. Transcrevemos o texto conforme a ordem de leitura espacial (i. e., da esquerda para a direita, de cima para baixo) que nos parece mais interessante:

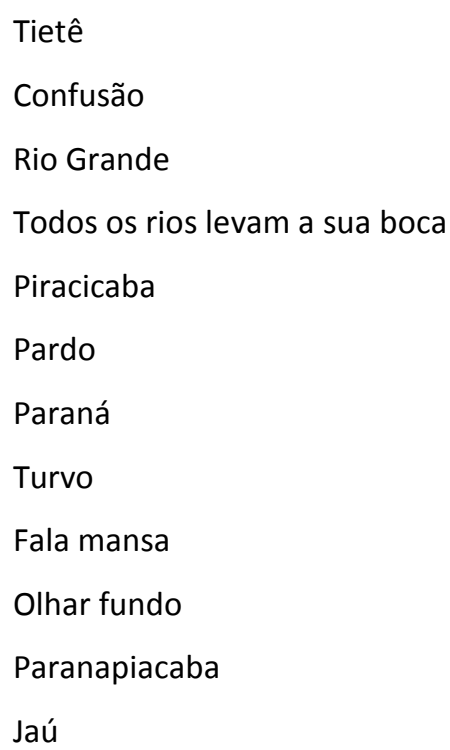




\section{Itu \\ Diana \\ O lago \\ O desejo}

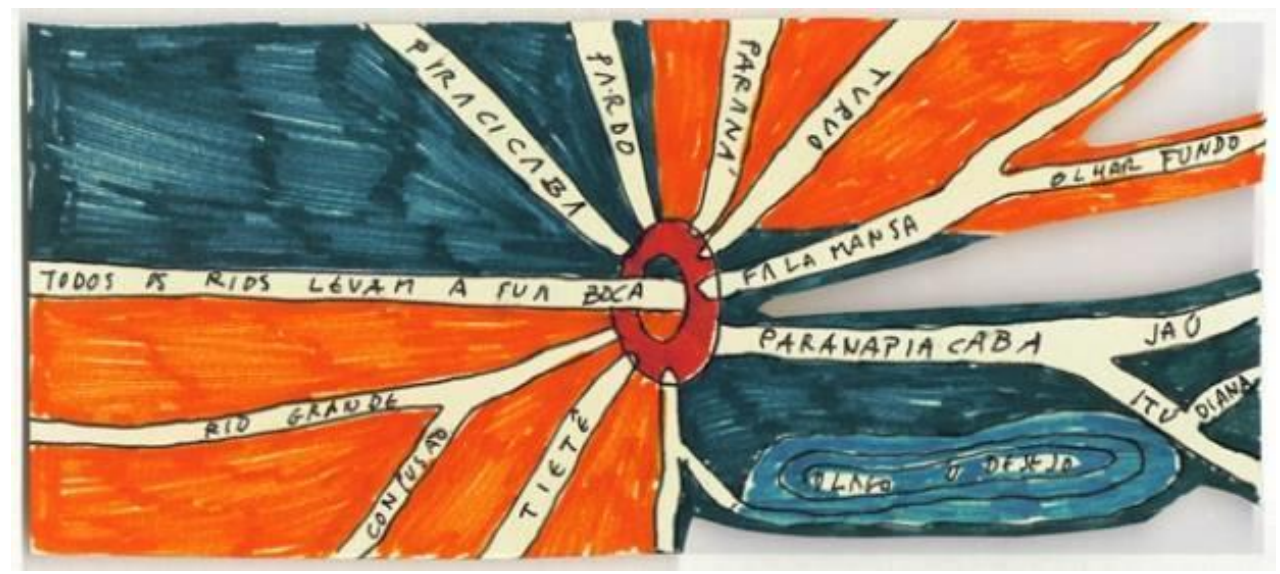

O procedimento linguístico (para além da força propriamente plástica da obra, aqui irrecuperável em todos os seus aspectos) obedece a um padrão curioso: em meio a substantivos próprios convencionais, que nomeiam rios brasileiros de tamanho e localização distinta, aparece um registro de linguagem diverso, surpreendente, uma passagem lírica em que também se faz notar a presença do erotismo: "Todos os rios levam a sua boca", um verso solto que vai se combinar com outras palavras e sugestões do texto/tela ("Confusão", "Fala mansa", "Olhar fundo"), todas elas convergindo para uma evocação enviesada, deslocada de fato, do desejo e das artimanhas da sedução. Em meio à aridez da cartografia, um corpo (uma voz) fala. A armação do texto, que alterna registros e combinações linguísticas (a descritividade seca dos nomes e a complexidade sintática e imagética do verso completo), irá também repercutir, de modo cumulativo e orgânico, na disposição visual da peça, que traz linhas convergentes, dentro das quais estão inscritos os versos da tela/texto, que se dirigem para um círculo em vermelho vivo no centro do quadro, aberto como uma boca, de onde saem todos os rios (e palavras) e para onde todas elas voltam, circularmente. O arranjo gradual da tela, por assim dizer, confere destaque à elaboração poética, que parece emergir da simples presença das palavras. Enquanto nos primeiros rios (nas primeiras linhas) aparecem apenas substantivos convencionais, à medida que o traço se dirige para o 
centro da peça a inscrição se torna mais densa, explodindo no verso principal, surgido de chofre, mas construído também pela sucessão de palavras e linhas que o precederam.

A construção conjunta do todo, ou seja, o inseparável do texto e da imagem, não subordina uma linguagem a outra nem condiciona um gênero ou outro de atividade criativa. As palavras não são acessórios ornamentais específicos ou guias explicativos para as imagens que se formam à flor da tela: há relativa autonomia de registros no que tange à elaboração do sentido, uma vez que, mesmo convergentes, o traçado e as cores podem ser analisadas, ao menos de maneira parcial, independentemente da incorporação e uso do registro escrito. É como se a letra viva, a palavra movente que persegue e estrutura tantos trabalhos de Leonilson e aqui se revela de modo simples e vigoroso, fosse uma espécie de suplemento (em sentido derridiano), um centro deslocado (e não transcendente) que não completa ou acrescenta um sentido incerto, mas amplia suas possibilidades ao criar uma nova zona autônoma de elaboração formal dentro da obra.

Assim como o que se pode notar aqui constitui-se como registro poético, outros textos/telas/objetos do artista possuem características e jogos formais similares. Referimonos a peças como "O pescador de pérolas" (1988), "Jogos perigosos" (1990) e "As cascas de ovo" (1992), para nomearmos apenas os bordados e as pinturas, deixando de lado as muitas gravuras e ilustrações do artista, todas elas costuradas em torno de palavras. Em "As oliveiras" (1990), por exemplo, tela em aquarela de dimensões médias, o artista esboça um salto mais amplo: ali Leonilson vai acumular palavras, sobrepor línguas e substantivos, construindo um texto no qual o verbal e o não verbal são radical e materialmente inseparáveis, mas no qual o gesto literário se impõe com força e assertividade, nos fazendo refletir, inclusive, sobre o que significa para o artista o gesto da escrita: nesse texto-tela, as palavras se espalham e acumulam, saltando por todos os lados, querendo dizer do sujeito, das suas impressões, das imagens que ele constrói a partir dos choques com o mundo. As listas e as anotações que se confundem com o desenho projetam desejos e sentidos sempre adiados e sempre presentes. A caligrafia e a pintura aqui são uma coisa só, escrever e pintar resultam do mesmo ato (a mão que traça linhas e produz rastros): trata-se de uma escrita que se faz antes com o corpo, que é traço material e físico do sujeito - além de circunvolução da inteligência -, incontrolável, nesse sentido, como a respiração ou as 
batidas do coração. Nessa confluência entre o sujeito da escrita e objeto da criação, é possível notar que as muitas letras na tela se misturam em transparência às manchas de tinta, segundo a forma leve da aquarela, deixando ver através de si o poema (e o desenho) em primeiro plano, numa técnica compositiva que vai privilegiar, justamente, a fusão e a superposição - a existência, enfim, de dois ou mais corpos (linguagens, obras, gêneros) num só espaço.

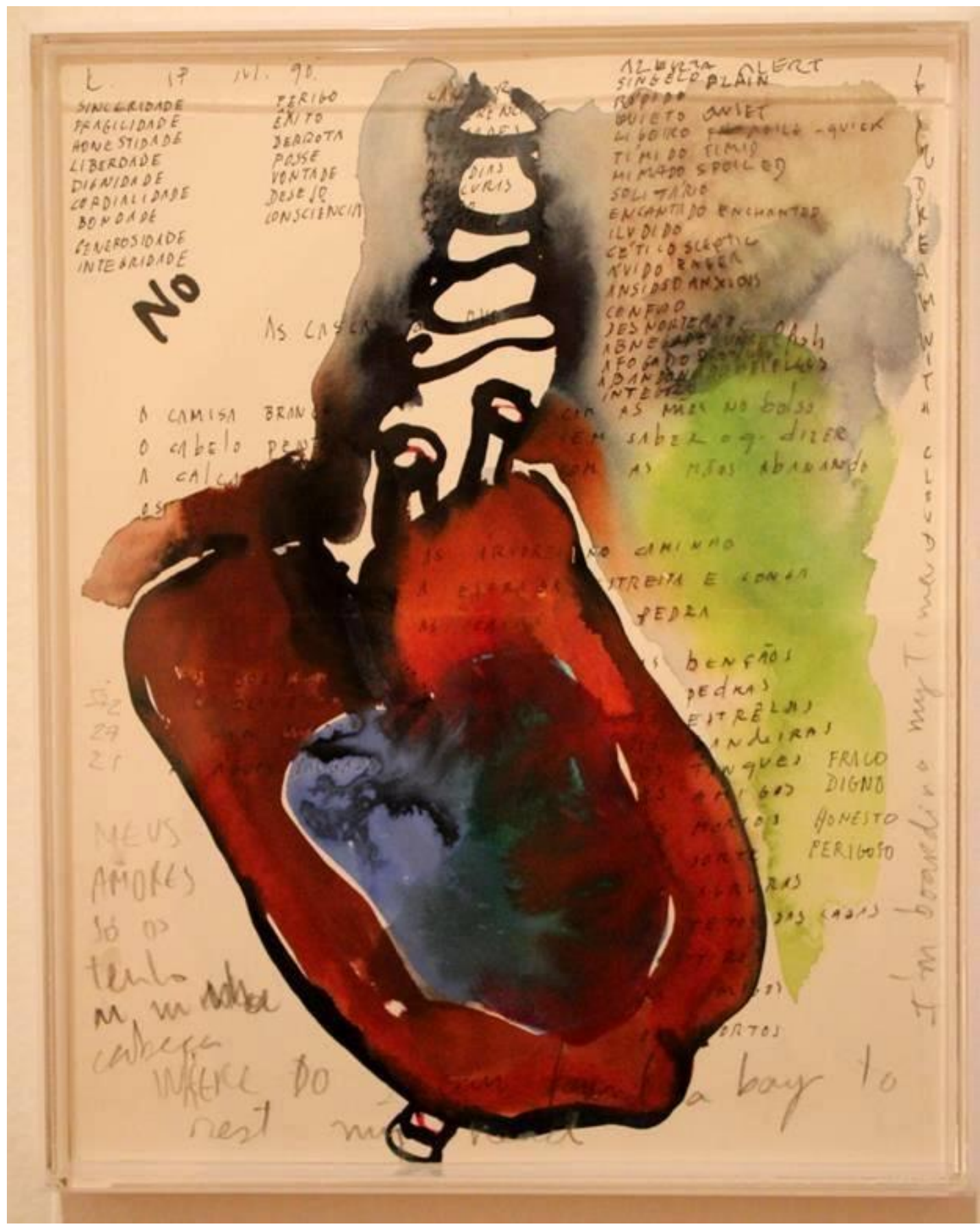


A partir de um imenso coração vermelho (nas proporções da tela), saem vasos comunicantes (e que vão dar nos limites do papel e na materialidade das palavras, apontando também para as linhas de fuga do corpo); no centro oco, uma mancha azulada se mistura ao desenho das letras, que, em formatos diferentes, se acumulam em relativa desordem. Numa superfície que lembra uma lista de anotações, Leonilson compõe fragmentos de poemas, pequenos versos dos quais se lê sempre apenas uma parte, mas que, pelo acúmulo e pela repetição, ganham força: substantivos e adjetivos ("dignidade", "derrota", "spoiled" etc.), pequenas frases que vão descrevendo o sujeito da escrita e os afetos que o atravessam, numa tentativa ao mesmo tempo de ordenar o caos interior - as listas vão assentando ideias, dando solidez ao que parece frágil e incerto - e expressar, lançar para fora de si pequenos arroubos, confissões, talvez, como a que vai quase num rabisco, grafia apressada, no canto esquerdo da tela: "Meus amores, só os tenho na cabeça". Os trechos manuscritos estão lado a lado com palavras em letra de forma, enumerando gestos de escritura e motivos recorrentes de seus trabalhos. A oposição entre termos de teor muito distinto, mas tantas vezes complementares, como "sinceridade" e "perigo", "liberdade e desejo", por exemplo, constitui temas centrais da obra do artista, além de apresentar uma constelação de conceitos que, nas listas e colunas seguintes, vão desaguar em versos melancólicos que indicam, de modo direto e descarnado, os estados contraditórios da paralisia, da afasia e do desconforto, nos quais o sujeito busca colocar-se, falar, mas não consegue tomar parte, equilibrar-se: "com as mãos nos bolsos/ sem saber o q. dizer". A palavra grafada com mais intensidade, que se mostra como que em destaque em meio às outras, "NO" (não), uma forma sintética e despojada de negativa, vai na mesma direção, dando ao quadro o tom ambíguo que o caracteriza, realização que permanece entre o poema e a forma-diário, o abertamente biográfico e a recusa do contato, da própria vontade de se expor. Coração opaco, conjunto de anotações imprecisas, quase um exercício livre de escrita e de imaginação, a tela é síntese dos procedimentos criativos do artista, apontando também para outras questões que atravessam o seu trabalho, como a relação com o diário, com os registros cotidianos dos acontecimentos, as narrativas de si que, em textos, telas ou gravações de áudio, ele foi construindo ao longo de quase toda a sua produção. 
Ao seguir nessa direção, ainda e sempre à procura de pensar as intersecções do trabalho de José Leonilson com as formas e elementos literários, recordo a proximidade de muitas das suas peças com a narratividade presente nos diários, forma de escrita/registro de si que o artista cultivou de diferentes maneiras. Curiosamente, os diários de Leonilson (assim mesmo, no plural, para dar visibilidade ao seu caráter vário e intermidiático, que vai das fitas-cassete elaboradas e arquivadas cuidadosamente às criações mais sutis, como "Ninguém" ou "34 com cicatrizes", nas quais entrechos e objetos do seu cotidiano são reencenados) constituem-se de textos fixados pelo artista entre 1990 e 1993 - os seus anos finais, quando a perspectiva da doença que o vitimaria, a Aids, já se anunciava no horizonte, primeiro como promessa fúnebre, e logo, a partir do exame feito em 1991, como realidade sombria e devastadora. A série de peças visuais em que se inscrevem também fragmentos do seu dia a dia costura delicadamente uma trama que oscila entre a ficção e a confissão, truth fiction, um jogo no qual os pequenos fatos de sua vida privada vão informando a fatura dos trabalhos sem jamais determinar os arranjos formais, os deslocamentos operados pela linguagem que a obra do artista executa: assim, as viagens, os encontros amorosos, as peças que vai compondo, as preocupações com a família e a saúde, elementos que jamais serão registrados de modo documental e direto em sua obra, aparecem, o mais das vezes, de modo elusivo e simbólico, ainda que a datação e os dados referenciais sejam reconhecíveis e até explicitados, como ocorre algumas vezes. Segundo Adriano Pedrosa, curador da exposição e do livro Truth, fiction.

Os diários compreendem o desejo e sua incompletude, os sonhos, as ilusões, as relações amorosas, as paixões platônicas e aquelas não correspondidas, os caminhos do rapaz apaixonado, o coração, os amantes e os amados - reais ou inventados -, bem como os autorretratos, a fantasia, a sexualidade, os dias e as horas que passam, a doença. (Pedrosa 2015: 16)

E essa multiplicidade de temas e questões está concretizada também nas muitas formas e materiais com os quais essa escrita do eu, essa narração continuada de si (que é também, como se sabe, invenção e performance permanente de si), vai se dar ao longo das obras, convidando a uma leitura poética das telas e bordados, de modo a mostrar como se revela pertinente ler o trabalho de Leonilson como uma forma expandida de exercício 
literário e de criação poética, conforme se pode ver, por fim, no quadro a seguir, "Deixou-se tombar", de 1988 (que muito irá antecipar os bordados feitos pelo artista logo depois, na sequência da sua carreira), puro gesto de escrita poético feito no suporte das artes plásticas, sem necessariamente - e essa distinção é importante - transformar-se exatamente num poema visual, como queriam, por exemplo, os poetas concretos de São Paulo.

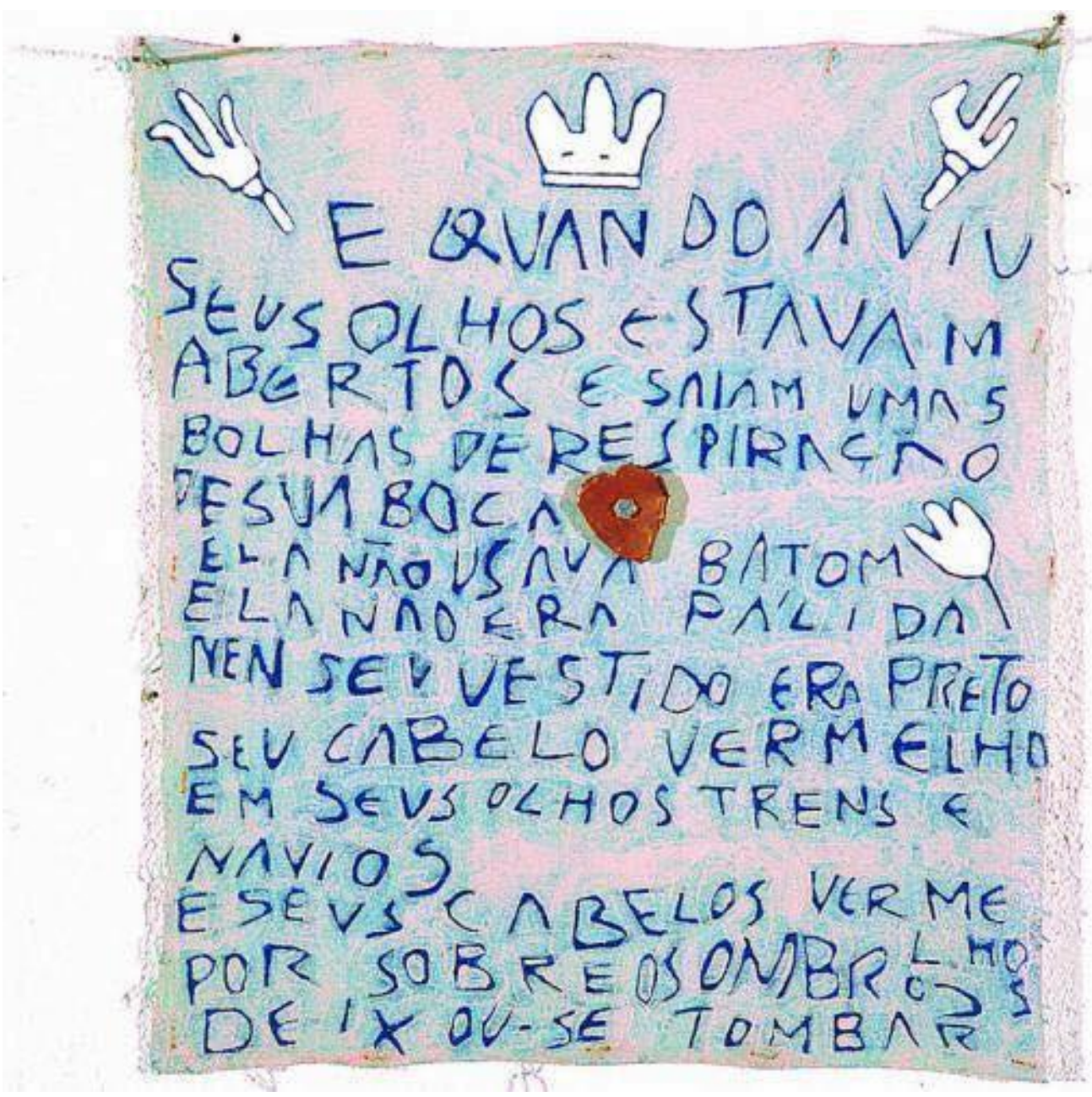

Mais do que constituir apoio ou complemento às imagens que compõem a tela em questão, aqui é o próprio texto, a letra mesma inscrita sobre a superfície do tecido, o centro sensível da obra. A cor, a disposição irregular das palavras, as marcas do pincel sobre o suporte, os fragmentos que compõem o poema, enfim, ocupam posição decisiva no quadro, que irá apresentar apenas mais uns pequenos desenhos junto ao texto (dois cetros brancos nas laterais, uma flor diminuta, uma coroa no alto da tela e um coração rubro ao centro, como que pregado), sem dar a eles, no entanto, qualquer destaque no conjunto da 
composição. É o poema o que interessa ao artista, o gesto da criação literária (e aqui pouco importa se se trata de uma citação transcrita ou um novo original composto) somado à representação direta da escrita como um processo e uma finalidade em si mesma, uma vez que, ainda que seja possível identificar certa estilização do traço e aguda consciência do espaço da tela, é o texto o que está em jogo, sobrevivendo e se impondo sem os recursos gráficos e padronizados da poesia concreta, apresentando ao espectador convencional de uma exposição de artes visuais a cena da leitura como modo de percepção fundamental e caminho para a sua fruição. O texto apresentado encena, em sua própria materialidade e nos sentidos que mobiliza, a contemplação e o desejo, o deslocamento provocado pelo olhar que descobre no outro o convite à metáfora, à imagem que desorganiza a racionalidade do pensamento e amplia os limites do sujeito que olha e do objeto desse olhar. Os "trens e navios" que se abrigam no rosto da mulher que está deitada, seus "cabelos vermelhos" sugerem a intensidade do encontro, a força do dado erótico que atravessa o poema. 0 aspecto errático das letras, que não seguem uma pauta linear nem respeitam uma padronização estrita, indica também, por sua vez, no plano formal, o elemento do descontrole e da irrupção (da contemplação inaugural) que vai apresentado pelo texto. A solidariedade entre ambas as instâncias é total: meio e mensagem - como ocorre sempre na poesia - são uma coisa só.

Em que pese o uso da tela e do bordado, da moldura e do desenho, Leonilson age aqui fundamentalmente como poeta, cujos versos, no entanto, ultrapassam a fronteira do livro e da página para habitar o tecido, a parede, o interior de um museu. Surgindo desde dentro das mídias e suportes propícios à visualidade e às operações do sensível típicas das artes plásticas, na obra do artista o poema parece ser produzido, por assim dizer, num movimento centrífugo, que vai do centro às margens, do interior ao exterior. Orgânica, a poesia cresce junto às imagens e traços, é parte deles, desdobra-se do seu interior, transbordando para todo o conjunto e além; faz-se com os mesmos recursos utilizados para desenhar uma figura de homem, bordar um contorno, tingir de cores uma tela em branco. 
NOTA

${ }^{1}$ Todas as traduções são do autor.

\section{Bibliografia}

Clemente, Gabriela Dias/ Ana Lenice Dias (orgs.) (2017), Leonilson: catálogo raisonné [3 vol.], São Paulo, Projeto Leonilson.

Derrida, Jacques (1986), Parages, Paris, Galilée.

Garramuño, Florencia (2014), Frutos estranhos, Rio de Janeiro, Rocco.

Krauss, Rosalind (1979), "Sculpture in the Expanded Field", October n. 8, MIT Press, 30-44.

Lagnado, Lisette (1998), Leonilson. São tantas as verdades, São Paulo, DBA Artes Gráficas.

Nancy, Jean-Luc (2005), Resistência da poesia, Tradução Bruno Duarte, Lisboa, Vendaval.

Pato, Ana (2013), Literatura expandida, São Paulo, Sesc.

Pedrosa, Adriano (2014), Leonilson: Truth, fiction, São Paulo, Pinacoteca do Estado; Rio de Janeiro, Cobogó.

Pucheu, Alberto (2014), Apoesia contemporânea, Rio de Janeiro, Azougue. 
Gustavo Silveira Ribeiro é professor de Literatura Brasileira da Faculdade de Letras da UFMG. Publicou, entre outros, os livros Antevéspera, noite interior (Macondo Edições 2018) [sobre a poesia de Age de Carvalho]; Poesia Contemporânea: Reconfigurações do sensível (Quixote + Do Editoras Associadas) e Toda a Orfandade do Mundo: Escritos sobre Roberto Bolaño (Relicário Edições 2016). Desenvolve atualmente projeto de pesquisa sobre as relações que certa poesia brasileira do presente mantém com a obra de Pier Paolo Pasolini. 